\title{
Spontaneous Pneumomediastinum, Pneumothorax and Pneumorrhachis Associated with Pneumocystis Jiroveci Pneumonia in HIV Positive Patient - A Rare Case Report
}

\author{
Deepak Garg ${ }^{1 *}$, NC Kajal ${ }^{2}$, Harveen Kaur ${ }^{1}$ and Divya Khanduja ${ }^{1}$ \\ ${ }^{1}$ Junior resident, Department of pulmonary medicine, Government Medical College Amritsar, India \\ ${ }^{2}$ Professor, Department of Pulmonary medicine, Government Medical College Amritsar, India
}

Submission: July 14, 2021; Published: August 02, 2021

*Corresponding author: Deepak Garg, junior resident, Department of Pulmonary Medicine, Government Medical College, Amritsar, Punjab, India.

\begin{abstract}
Pneumocystis jirovecii is a unicellular and eukaryotic organism that causes pneumocystis in humans. With the use of highly active antiretroviral therapy (HAART) and the chemoprophylaxis with trimethoprim and sulfamethoxazole, the overall incidence of pneumocystis jirovecii pneumonia has been decreased. With advanced HIV infection, approximately $85 \%$ of the patients experience PCP in the course of the diseases. Pneumocystis infection can present with spontaneous pneumothorax in $35 \%$ of the patient and with pneumomediastinum in $0.4 \%-3.3 \%$ of population which can be a potentially fatal condition. Pneumorrhachis is a radiological finding. Pneumorrhachis without associated trauma and surgical intervention is rare. We report the case of 16-year-old HIV positive child who developed bilateral pneumothorax, pneumomediastinum and pneumorrhachis.
\end{abstract}

Keywords: Pneumomediastinum; Pneumothorax; HIV infection; Pneumorrhachis; Pneumocystis jirovecii pneumonia

Abbreviations: PR: Pneumorrhachis HAART: Highly Active Antiretroviral Therapy; COPD: Chronic Ob $\neg$ structive Pulmonary Diseases; TLC: Total Leukocyte Count; DLC: Differential Count; ABG: Arterial Blood Gas; PJP: Pneumocystis Jirovecii Pneumonia

\section{Introduction}

Pneumocystis pneumonia is a common opportunistic infection in the patients with AIDS and low CD4 counts $<200$ cells $/ \mathrm{mm}^{3}$.The spontaneous pneumothorax (the presence of air in the pleural cavity) is a frequent complication in patients with Pneumocystis jirovecii pneumonia since it was first described in 1984 [1]. Spontaneous pneumothorax occurs in up to $35 \%$ of patients with $P$. jirovecii pneumonia. Spontaneous pneumothorax that occurs in patients with underlying lung diseases, such as chronic obstructive pulmonary diseases (COPD), cystic fibrosis, or $P$. jirovecii pneumonia, is termed secondary spontaneous pneumothorax and considered a potentially life-threatening condition $[2,3]$.

However, pneumomediastinum-the presence of air in the mediastinum is an unusual complication in pneumocystis jirovecii pneumonia with prevalence ranging from $0.4 \%$ to $3.3 \%$. The spontaneous pneumomediastinum occurs due to abrupt increase in the transalveolar pressure gradient, as seen during violent coughing. The spontaneous pneumomediastinum sometimes accompanied with subcutaneous emphysema and pneumorrhachis. The pneumorrhachis is defined as the presence of air in the spinal canal. It is also known as epidural emphysema. We report a case of bilateral pneumothorax, pneumomediastinum and pneumorrhachis in a patient with HIV seropositivity.

\section{Case Report}

A 16 year old male presented to the emergency department of CHEST AND TB hospital, Amritsar with chief complaints of difficulty in breathing from 2 days, fever since 7 days, cough and chest pain from 6 days. The symptoms progressively worsened and became severe one night prior to admission (Figure 1). The patient had been diagnosed with HIV for 2 years. The attendants of the patient denied history of any trauma, allergies, travelling 
or similar episodes in the past. Both the father and the mother of the child were HIV positive. No history of lumber puncture. On examination the pulse rate $-140 / \mathrm{min}, \mathrm{RR}-34$ breaths $/ \mathrm{min}, \mathrm{SPO}_{2}$ $70 \%$ on room air, BP- 90/60.

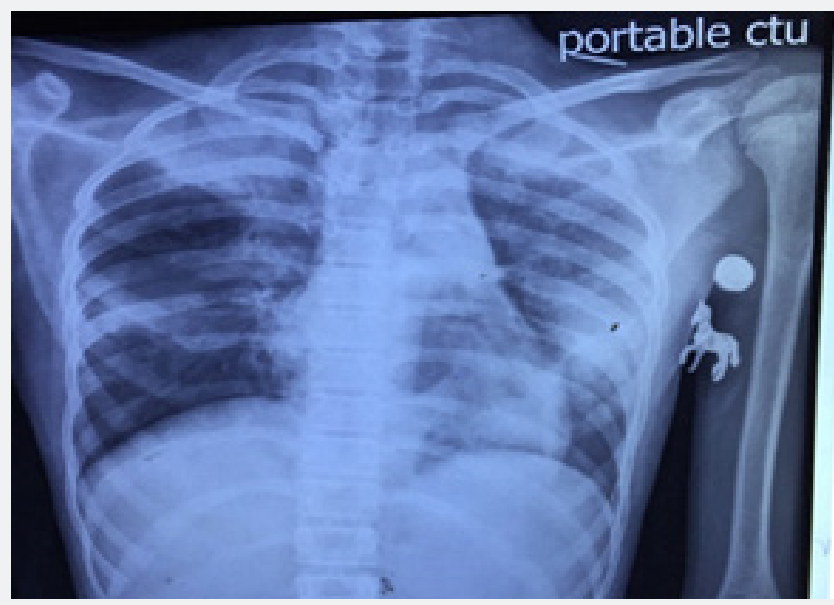

Figure 1: Chest x-ray AP view of 16 year old child showing Bilateral Pneumothorax with pneumomediastinum with homogenous Opacity in the right upper lobe with bilateral diffuse infilteration.

The patient was put on nonrebreather mask and the saturation on NRB mask improved to $95 \%$. On palpation, there was minimal crepitus over the neck and on auscultation there were reduced breath sounds bilaterally with coarse crepitations with rhonchi in left interscapular area. The blood investigations revealed TLC (total leukocyte count)- 12,580, DLC (Differential count)Neutrophils-85/lymphocytes 11/monocytes-3/eosinophils-1/ basophil-1, Hb-8.7, platelet count-3.16, S. CREATININE-0.76, CRP levels were 78.4, HCV-NON-REACTIVE, HBsAg- negative. Sputum for AFB- negative, sputum for CBNAAT- MTB not detected, sputum for fungus- no growth, sputum for gram stain and culture sensitivity- no growth detected.
The ABG (arterial blood gas) analysis on NRB mask revealed pH-7.19, PC02-77.92, PO2-86.69, HCO3-30.22 that is, respiratory acidosis with compensation. CHEST X RAY-AP view shows bilateral diffuse reticular infilterates with bilateral pneumothorax. HRCT revealed diffuse ground glass haze with patchy areas of GGO's and consolidation with bilateral pneumothorax, pneumomediastinum and pneumorrhachis. The patient was started on INJ. METHYL PREDNISOLONE and TAB. BACTRIUM DS and TAB EFAVIRENZ. Bronchoscopy was planned and bronchial washings confirmed the presence of pneumocystis jirovecii pneumonia on Gomori methenamine silver stain (Figure 2). On day $11^{\text {th }}$ patient saturation level drops to $60 \%$ but attendants did not give consent for invasive ventilation and the patient died of respiratory distress (Figure 3).

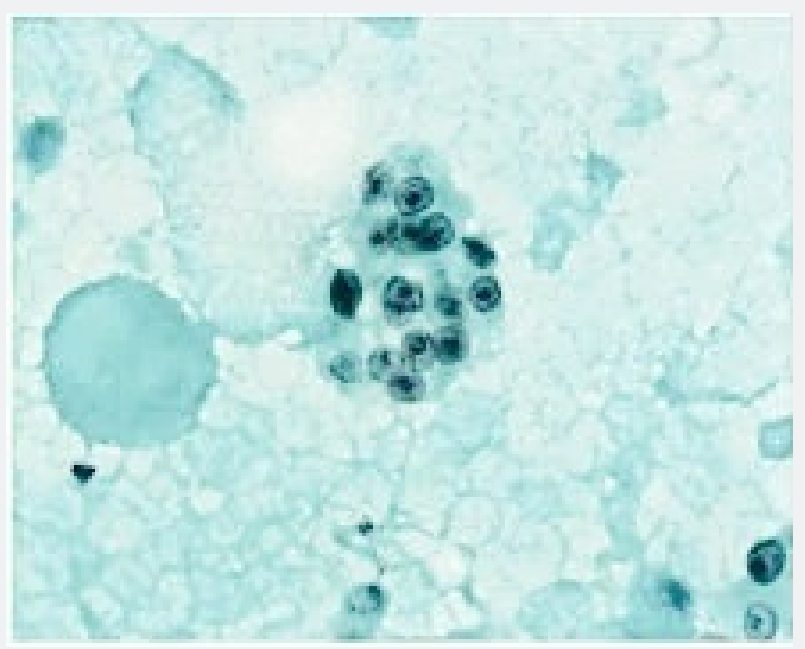

Figure 2: Microscopic picture of pneumocystis Jirovecii cysts on Gomori methenamine. Silver stain of bronchial washings. 


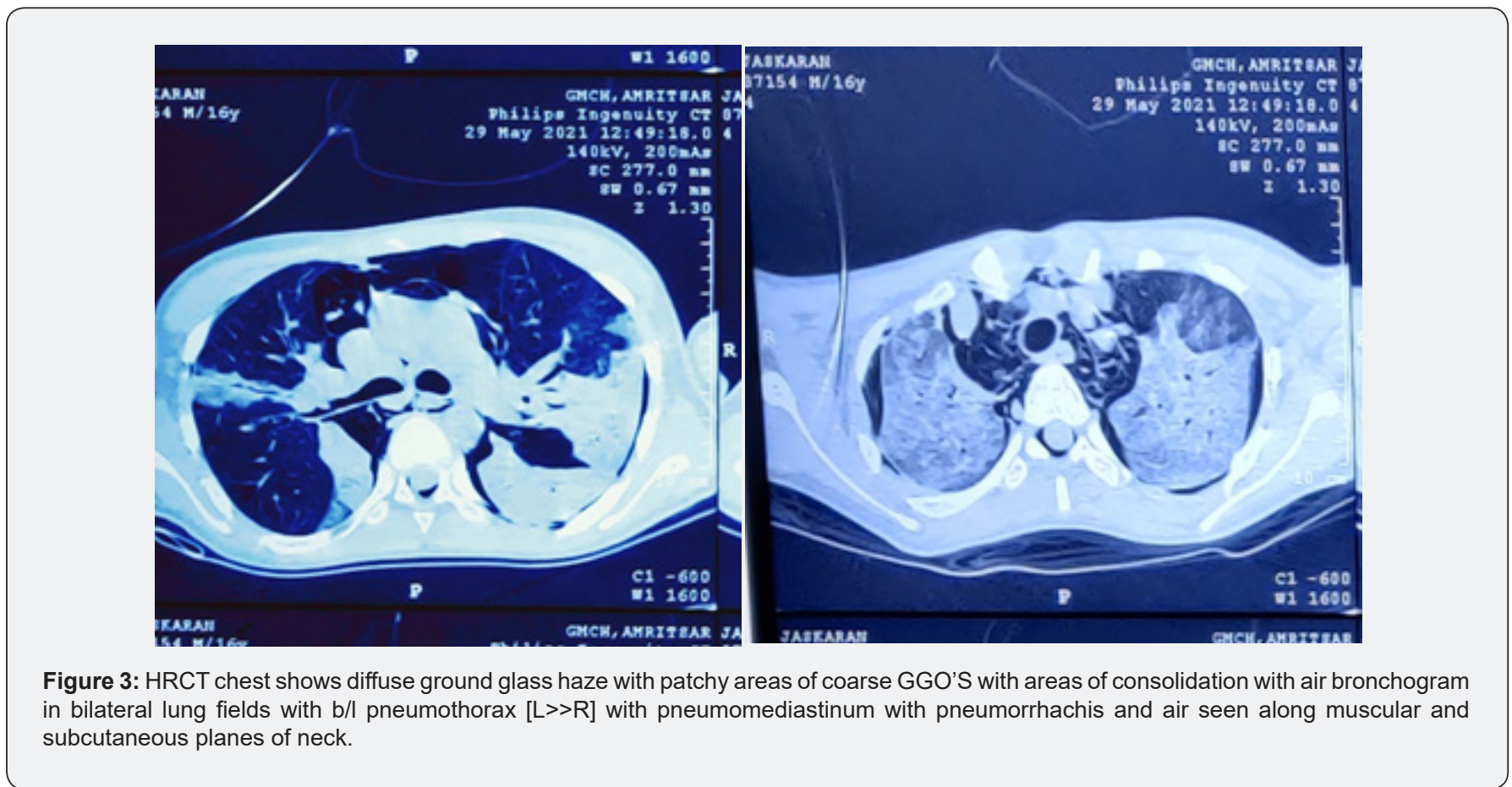

\section{Discussion}

The leading cause of morbidity and mortality in patients with HIV are the pulmonary complications. The most common cause of pulmonary complications in HIV infected with CD4 count $<200$ cells $/ \mathrm{ml}$ is pneumocystis jirovecii pneumonia (PJP). Diffuse interstitial infilteration are the common radiographic findings but some atypical presentations such as cystic, nodular and pneumothorax have been reported. In the era of HAART, the overall incidence of PJP have been decreased [4]. Still, 85\% of the population continue to suffer from PJP in the course of disease with severe HIV infection.

Pneumomediastinum is a rare but severe complication of pneumocystis jirovecii pneumonia with HIV infection with prevalence of $0.4 \%$ to $3.3 \%$ [5-7]. Macklin in 1944, explained that the pneumomediastinum is caused due to increase in the alveolar pressure that causes the alveoli to rupture, and thereby releasing the air and causing to through the peribronchial and perivascular sheaths of the mediastinum [8]. Another reason could be abnormal increase of pressure in the mediastinum, which the pleural cavity is subjected to low and negative pressure, causing air to dissect in between the mediastinal structures, which support the mediastinal organs. A dramatic decrease in intravascular pressure also can create a relative pressure gradient in the perivascular spaces [9]. The air may then dissect to the neck, upper abdomen or the skin via the loose alveolar fat tissue (subcutaneous emphysema) [10]. Air can also pass the pleura resulting in pneumothorax or the peritoneum resulting in pneumoperitoneum [11].

The clinical presentation of the pneumomediastinum is benign and self-limiting. Chest pain-pleuritic and retrosternal and dyspnoea are the common presenting symptoms. CT CHEST is the gold standard investigation for diagnosis. Bronchoscopy, endoscopy or barium swallow should be done if suspicion for aerodigestive tract perforation is high. The management of patients with spontaneous pneumomediastinum is conservative, consisting of rest, analgesics, and close observation. Although pneumomediastinum is benign, the risk of tension pneumomediastinum or pneumothorax justifies close clinical observation

Pneumorrhachis is usually an asymptomatic radiological finding [12]. Pneumorrhachis without associated trauma or intervention is rare [13]. It can be either intradural or extradural and on etiological basis can be divided into iatrogenic, traumatic, and non-traumatic PR. Our patient developed pneumomediastinum, bilateral pneumothorax, pneumorrhachis and surgical emphysema in the absence of any trauma. In our case, we gave antimicrobial therapy and steroids for $P$. jirovecii pneumonia early and adopted a conservative strategy, but patient could not be survived.

\section{Conclusion}

PCP has abrupt symptom onset with rapid progression and carries a high mortality. Spontaneous pneumomediastinum and surgical emphysema is a rare complication in patient of pneumocystis jirovecii pneumonia with HIV infection and warrant close monitoring as they portend poor prognosis. Although pneumomediastinum and pneumothorax has been described in relation with PCP, concurrent pneumorrhachis related to same etiology has rarely been reported. 


\section{References}

1. Stringer JR, Beard CB, Miller RF, Wakefield AE (2002) A new name (Pneumocystis jirovecii) for Pneumocystis from humans. Emerg Infect Dis 8(9): 891-896.

2. Baumann MH, Noppen M (2004) Pneumothorax. Respirology 9(2): 157-164.

3. Mc Clellan MD, Miller SB, Parsons PE, Cohn DL (1991) Pneumothorax with Pneumocystis carinii pneumonia in AIDS. Incidence and clinical characteristics. Chest 100(5): 1224-1228.

4. Palella Jr FJ, Delaney KM, Moorman AC, Loveless MO, Fuhrer J, et al. (1998) Declining morbidity and mortality among patients with advanced human immunodeficiency virus infection. HIV Outpatient Study Investigators. N Engl J Med 338(13): 853-860.

5. De Lorenzo LJ, Huang CT, Maguire GP, Stone DJ (1987) Roentgenographic patterns of Pneumocystis carinii pneumonia in 104 patients with AIDS Chest 91(3): 323-327.

6. Hidalgo A, Falco V, Mauleon S, Andreu J, Crespo M, et al. (2003) Accuracy of high-resolution CT in distinguishing between Pneumocystis carinii pneumonia and non-Pneumocystis carinii pneumonia in AIDS patients. Eur Radiol 13(5): 1179-1184.

7. Rivero A, Perez-C I, Lozano F, Santos J, Camacho A, et al. (2009) Etiology of spontaneous pneumothorax in 105 HIV-infected patients without highly active antiretroviral therapy. Eur J Radiol 71(2): 264-268.

8. Macklin MT, Macklin CC (1944) Malignant interstitial emphysema of the lungs and mediastinum as an important occult complication in many respiratory diseases and other conditions: an interpretation of the clinical literature in the light of laboratory experiment. Medicine.

9. Agut A, Talavera J, Buendia A, Agustina A, Giorgia S, et al. (2015) Imaging diagnosis-spontaneous pneumomediastinum secondary to primary pulmonary pathology in a dalmatian dog. Vet Radiol Ultrasound 56(5): E54-7.

10. Russo A, Del Vecchio C, Zaottini A, C Giangregorio (2012) Role of emergency thoracic ultrasonography in spontaneous pneumomediastinum. Two case report. G Chir 33(8-9): 285-296.

11. Pooyan P, Puruckherr M, Summers JA, Ryland PB Jr, Thomas MR (2004) Pneumomediastinum, pneumopericardium, and epidural pneumatosis in DKA. J Diabetes Complications 18(4): 242-247.

12. Oertel MF, Korinth MC, Reinges MH, Krings T, Terbeck S, et al. (2006) Pathogenesis, diagnosis and management of pneumorrhachis. Eur Spine J 15(Suppl 5): 636-643.

13. Okoh S, Gopal KV (2008) Pneumothorax in Pneumocystis jiroveci pneumonia: a case report, review of clinical characteristics and management. Am J Case Rep 9: 120-124.

Your next submission with Juniper Publishers will reach you the below assets

- Quality Editorial service

- Swift Peer Review

- Reprints availability

- E-prints Service

- Manuscript Podcast for convenient understanding

- Global attainment for your research

- Manuscript accessibility in different formats

(Pdf, E-pub, Full Text, Audio)

- Unceasing customer service

Track the below URL for one-step submission https://juniperpublishers.com/online-submission.php 